\title{
Imágenes en movimiento: de la palabra escrita a la representación pictórica
}

\author{
Amelia R. MAÑAS \\ Universidad Autónoma de Madrid \\ amelia.r.mannas@gmail.com
}

\begin{abstract}
RESUMEN
Han sido muchos los que, alentados por el conocido lema horaciano ut pictura poesis, iniciaron una comparación entre pintura y poesía. Este artículo pretende descubrir y reconocer cómo pintura y poesía han tratado de sugerir la sensación de movimiento, cómo cada una de ellas ha sido capaz de trasladarlo y recrearlo con sus propios medios expresivos. Para ello analizaremos las diferentes formas en las que la imagen ha sido construida en pintura y poesía con la intención de conducirnos hasta esa noción de desplazamiento. Empezaremos con algunos ejemplos previos para centrarnos después en el siglo XX, donde la variedad de propuestas se enriqueció de sobremanera.
\end{abstract}

Palabras clave: movimiento, ritmo, discontinuidad, pintura, poesía.

\begin{abstract}
There have been many who, encouraged by the Horace's well known words ut pictura poesis, initiated a comparison between painting and poetry. This article intends to discover how painting and poetry suggest the movement sensation, how they translate it to their own way of expression. In order to do this, we will analyze the different ways in which the image has been built in painting and poetry to lead us to this notion of displacement. We will begin with some previous examples to reach and focus on Twentieth century, where the variety of the proposals got highly increased and enriched in both mediums.
\end{abstract}

Keywords: movement, rhythm, discontinuity, painting, poetry.

Ut pictura poesis o el parangón entre las artes. Cuando uno se dispone a abordar un determinado estudio que se ocupe de las posibles relaciones entre la literatura y las artes visuales se encuentra, muy a menudo, con la presencia de ciertas trabas. Una y otra vez reaparecen, y siempre de la misma manera. Horacio, Simónides de Ceos y Plutarco, o los pintores y poetas del Renacimiento y Barroco, Burke, Lessing y Baudelaire serán sólo alguno de los nombres que vendrán a enseñarnos, con cada uno de sus testimonios, la compleja realidad de la cuestión. Pues han sido tan- 
tos y tantos otros los que vieron en este dialogismo un terreno fecundo que no podemos menos que sorprendernos ante la relativa falta de consenso, los continuos virajes en el discurso en favor de la primacía de alguna de las dos o la total falta de un modelo de lectura que pueda ser aplicado de manera general. No hay un corpus firme y estable al que volver en busca de la autoridad necesaria. Y no lo hay, de hecho, porque no encontramos en ellos un único proceder que pueda dar la clave a una solución definitiva.

Sí es cierto, por ejemplo, que los semióticos pretendieron un acercamiento de carácter científico y universal, aplicando un paradigma lingüístico a objetos no necesariamente lingüísticos. Sin embargo, la crítica que tradicionalmente se les ha hecho, pese a reconocer lo beneficioso de su proyecto, reside, precisamente, en la distinción entre el grado de semejanza con respecto al modelo natural y el grado de convención que reside en el establecimiento del signo. En relación a ello W. J. T. Mitchell ${ }^{1}$ considera que este tipo de sistemas de clasificación resultan altamente distintivos —o disyuntivos, podríamos decir-, de manera que una vez definido el signo, pictórico o lingüístico, en función de la semejanza y la convención, éste termina ocupando una categoría difícilmente intercambiable. Y en un mundo como el nuestro, donde la experimentación está a la orden del día y donde continuamente surge la necesidad de encontrar nuevos formatos, se hace necesario un sistema más flexible, que deje lugar también a la fluidificación de las fronteras entre el arte y la literatura. Por esta razón, si bien tomaremos las enseñanzas de Barthes ${ }^{2}$, para el que cada obra de arte operaba como un texto, organizado en torno al signo, desearemos tener en cuenta no sólo esta circunstancia sino las condiciones en que fueron creadas. Condiciones que impone cada medio y que obligarán, por tanto, a un uso diferente de los recursos en la codificación y transmisión del mensaje.

Uno podría preguntarse por qué pintura y poesía, y por qué no música, por qué iniciar este trabajo en un querer emparentar imagen y texto cuando la música ofrece, a todas luces, lugares de mayor proximidad y encuentro con la poesía. Tal vez por aquello de que ésta última no está tan sujeta a la intención de comunicar un significado cuanto una emoción. Tal vez por aquello de que el sonido y el ritmo de la misma hablan desde una afinidad que no podría ser más radicalmente opuesta a la que se da entre pintura y poesía. Ambas, obras del espíritu, salidas de lo más íntimo, operan en medios distintos, el suyo es el reino de la diferencia. Si la primera apela al mundo de lo visible y los objetos tangibles, la segunda lo hace al de lo inmaterial de las ideas y la representación simbólica. Para Mitchell no será tanto un problema de símbolos sino de cómo cada una de ellas llega hasta nosotros, las vías por las que tiene lugar la revelación de lo poético: «The paragone or debate of poetry and pain-

\footnotetext{
${ }^{1}$ W. J. T. Mitchell (1992).

${ }^{2}$ R. Barthes (2009).
} 
ting is never just a content between two kinds of sings, but a struggle between body and soul, world and mind, nature and culture» ${ }^{3}$.

En el caso concreto que nos ocupa, el fenómeno del movimiento o su reproducción, la manera en que es sugerido en pintura y poesía, quisiéramos, primero de todo, recordar las reflexiones de Heinrich Wölfflin ${ }^{4}$, para quien la sucesión de los estilos fue más bien una cuestión de alternancia de espíritus. Contraponiendo Renacimiento y Barroco, vio una misma dialéctica relación entre lo apolíneo y calmado, y la expresión de las pasiones en la evolución de los movimientos artísticos, literarios incluidos. Algo así como un ir y venir del equilibrio de la razón que deja paso a la emoción y a la agitación turbulenta. Para apoyar su teoría acudió a ejemplos como las esculturas del David de Miguel Ángel y el David de Bernini. Halló en la elección miguelangelesca del momento previo a la acción, como de gravedad introspectiva o el pensar adentro, una decisión marcada por el espíritu de la época que difería de las preocupaciones o aspiraciones del Barroco. Bernini, en cambio, parecía más interesado en el hecho mismo de la acción, en aquel movimiento que se extiende casi hasta lo ilimitado, una sensación de dinamismo que reaparecería en casi todas sus obras y muy especialmente en la escultura de Apolo y Dafne (ver Figura 1).

Cuando Quevedo se disponga a tratar este mismo tema en una de sus composiciones, nos ofrecerá primero a la ninfa huyendo del dios que la pretende: «Delante del Sol venía / corriendo Dafne, doncella / de extrema gallardía, / y en ir delante tan bella, / nueva Aurora parecía», para continuar con un Apolo decidido a no abandonar: «Cansado más de cansalla / que de cansarse a sí Febo, / a la amorosa batalla / quiso dar principio nueuo, / para mejor alcançalla». Pese a los esfuerzos de éste, el poeta introducirá, como complace al mito, a la figura del padre, Peneo, que será quien interceda por su hija: «Pero su padre, zeloso, / en su curso cristalino / tras ella corrió furioso, / y en medio de su camino / los atajó sonoroso». Prosigue Quevedo con las súplicas del dios: «Di, ¿por qué mi dolor creces / huyendo tanto de mí / en la muerte que me ofreces?», hasta que finalmente tiene lugar la transformación «escondióse en la corteza» y «con vn honesto temblor, / por rehusar sus abraços, / se quexó de su rigor» ${ }^{5}$.

\footnotetext{
${ }^{3}$ W. J. T. Mitchell (1992), p. 49.

${ }^{4}$ H. Wölfflin (1986).

${ }^{5}$ F. de Quevedo (2006), pp. 199-202.
} 


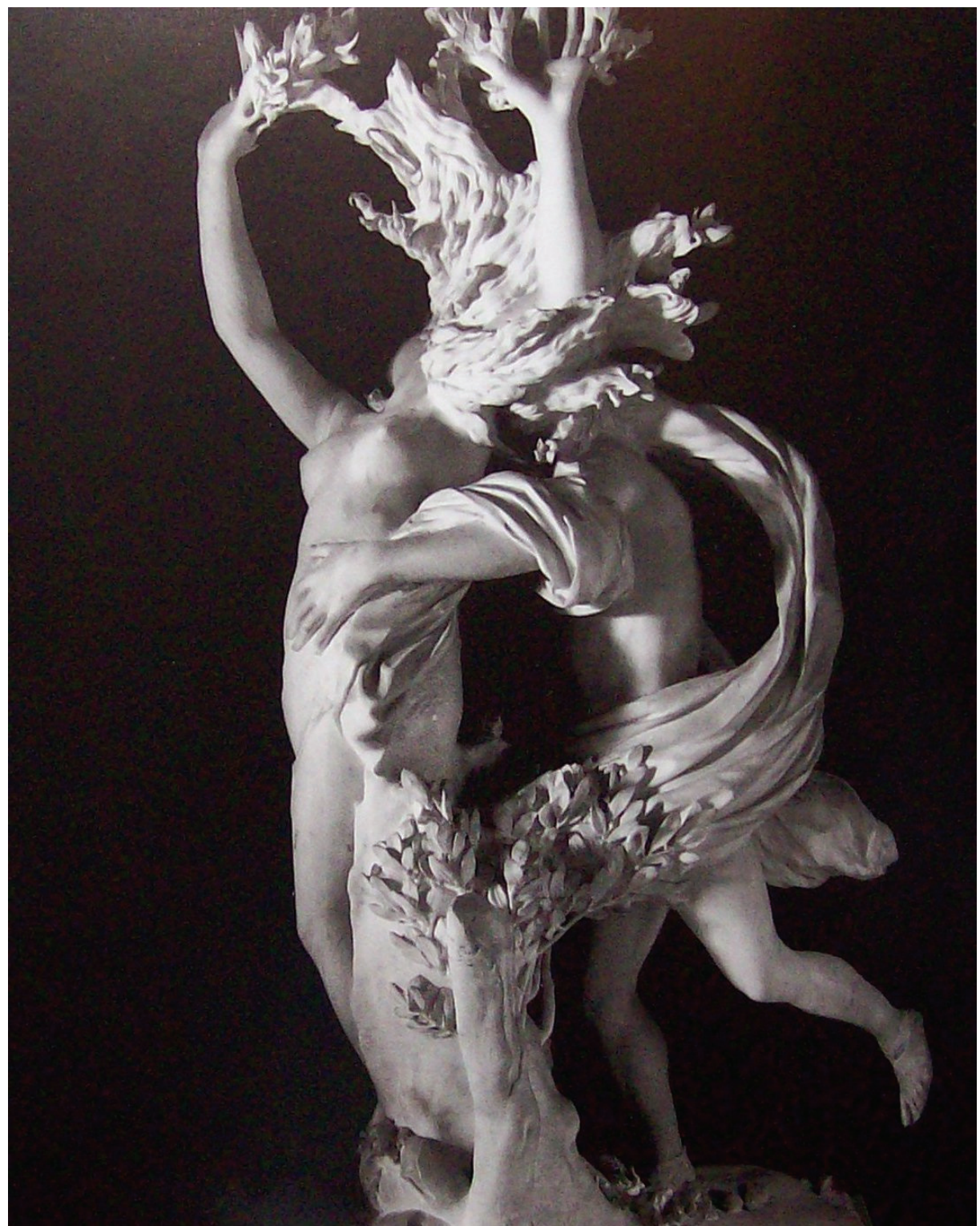

Figura 1. Apolo y Dafne, Bernini, Galería Borghese, 1622-1625. 
Mientras que el escultor debía optar por uno de los momentos de la fábula, el más representativo o el que más conviniese a su proyecto, el poeta pudo extenderse, contar lo que ocurría. A diferencia de la pintura o la escultura, el poema alcanza a elaborar más de una idea que, además, crece y se hace compleja y se enriquece del resto con las que se relaciona. Está mejor capacitado para representar toda una historia. El movimiento no sólo será sugerido semánticamente con las palabras huir, correr o atajar, que podemos encontrar entre sus versos. La poesía misma, como la literatura, permite ese avanzar en el tiempo de imagen tras imagen que se cumple con la lectura sucesiva. Su dominio es el de lo inefable, y el espacio para su concreción no será el espacio físico visible. Las palabras, en tanto signos, simbolizan a partir de «algo que además de la imagen asimilada por los sentidos, hace venir por sí misma al pensamiento alguna otra cosa» ${ }^{6}$. Frente a la corporeidad de los elementos de la escultura, lo inmaterial de la imagen mental de la palabra que, por sí misma y en comunión con las demás, es capaz de convocar. De ahí una diferencia fundamental entre estas dos artes, pues lo ilimitado de la literatura, del espacio abstracto en el que se cumple y que permite una recreación a lo largo del tiempo — para la que será necesaria la intervención de la memoria-, difiere drásticamente del carácter restringido o limitado de las artes visuales.

El escultor deberá lidiar, entonces, con esa condición de inmediatez que reviste al signo pictórico, pues una vez que aparece en el campo visual, lo hace de manera completa y total. En su intento por reproducir la sensación de movimiento, el artista, al menos todavía del Barroco, es incapaz de fragmentar y, por ello, de dar cuenta de ese discurrir en el tiempo que es el movimiento ${ }^{7}$. Lo que sí podrá hacer es sugerirlo a partir de lo que Deleuze, en su comentario a Bergson, denominó como instantes privilegiados o poses $^{8}$. Una vez seleccionados, el escultor emulará ese impulso o esa energía dinámica a partir del reparto de los pesos y las líneas de fuerza o las diagonales que actúan sobre la materia rompiéndola en varios flancos. Es decir, a partir de un uso enfático de los elementos que caracterizan a la escultura: el volumen, la masa y la luz.

\footnotetext{
${ }^{6}$ R. Barthes (2009), p. 49.

${ }^{7}$ Deleuze comienza su libro La imagen-movimiento. Estudios sobre cine I especificando que no se debe confundir movimiento con espacio recorrido: «El espacio recorrido es pasado, el movimiento es presente, es el acto de recorrer. El espacio recorrido es divisible, e incluso infinitamente divisible, mientras que el movimiento es indivisible, o bien no se divide sin cambiar, con cada división, de naturaleza», en G. Deleuze (2012), p. 13.

${ }^{8}$ El filósofo francés continúa su exposición a través de lo que ha significado el movimiento en la Antigüedad, concebido como el punto más cercano en el que las Ideas o las Formas llegan a actualizarse en la materia. Éstas son potencialidades que «no pasan al acto más que encarnándose en la materia». El cambio regulado de una forma a otra aparecerá regido por «un orden de las poses o los instantes privilegiados», en G. Deleuze (2012), p. 17.
} 
De igual forma ocurrirá en literatura, se tendrá que trabajar a partir de un uso enfático de las cualidades intrínsecas del lenguaje. La poesía, aun con más motivo, hará de la alianza entre el contenido semántico y las propiedades fónicas y musicales de la lengua la manera con que «acrecentar el poder y la penetración de la palabra» ${ }^{9}$. En las quintillas de Quevedo, con rima $a b a b a$, $a b b a b$ y $a b a a b$, el acento esencial irá, como es habitual, en séptima, y será precedido por otros acentos en segunda y tercera como en: «El Sol corre por seguirla, / por huir corre la estrella». O incluso en primera y tercera: «corre el llanto por no verla, / corre el aire por oírla». Y de nuevo, en segunda: «y el río por socorrerla». Vemos entonces que será no sólo la rima sino los acentos lo que otorgue esa fluidez que da vida a la estrofa. A pesar de que actualmente muchos han rechazado el uso extremo de la retórica antigua, por correr el riesgo de reducir la poesía a una serie de fórmulas y normas que más que liberarla la oprimieran, anquilosando y apresando su ritmo — «hay máquinas de rimar pero no de poetizar» ${ }^{10}$, decía Octavio Paz - no debemos olvidar que la métrica tradicional trató de codificar todas esas variaciones de tono, cantidad e intensidad de los elementos y sus reiteraciones en un juego de cadencias basado «forzosamente en un ritmo» ${ }^{11}$.

Así pues, el ritmo como fuerza primordial que alienta a la poesía, pero también un ritmo que será unidad de sentido, que se llenará de significado. No podrá darse lo uno sin lo otro. Valéry hacía referencia a las condiciones «musicales, racionales, significativas y sugestivas [que] exigen una relación continuada y persistente entre un ritmo y una sintaxis, entre el sonido y el sentido» ${ }^{12}$. Y Paz lo calificaba como ese elemento que dota, precisamente, de dirección y sentido. Aquello que nos coloca en una disposición de ánimo, como a la espera de lo que vendrá, y que se irá revelando a través de los sucesivos vaivenes a los que seremos sometidos. Para Octavio Paz el ritmo será esencialmente movimiento, especie de ímpetu o imán que convoca las palabras y las obliga a disponerse una tras otra, en el orden correcto: «Las palabras se juntan [...] atendiendo a ciertos principios rítmicos. [...] El dinamismo del lenguaje lleva al poeta a crear su universo verbal utilizando las mismas fuerzas de atracción y repulsión» ${ }^{13}$. Como un frágil fluir, una corriente mágica por donde todo va y viene, por donde todo surge, la vida finalmente se hace: «El verso, la fraseritmo, evoca, resucita, despierta, recrea [...], revive nuestra experiencia de lo re$a \mathrm{l} \gg{ }^{14}$. Nos invita a leer, a sumergirnos y pasar de una palabra a la siguiente, a descubrir guiados por ese movimiento que nos empuja siempre hacia delante en las

${ }^{9}$ P. Valéry (1975), p. 17.

${ }^{10}$ O. Paz (2008), p. 14.

${ }^{11}$ E. Varela, P. Moíno y P. Jauralde (2005), p. 20.

${ }^{12}$ P. Valéry (1975), p. 57.

${ }^{13}$ O. Paz (2008), p. 53.

${ }^{14}$ O. Paz (2008), p. 109. 
distintas formas, imágenes, a través de las que se cumple. Y por siempre hacia delante entenderemos no un movimiento lineal sino continuo, que no para, que se actualiza y reactualiza continuamente, que se vuelve sobre el principio, sobre sí mismo, y que nos empuja. Nos empuja a nosotros y a las palabras. Es un movimiento de lectura pero también de vida. Por él las palabras o los vocablos vuelven a ser, abandonan su quietud y reconquistan su lugar en el mundo, se hacen, al fin, visión concreta de ese mundo ${ }^{15}$.

El ritmo será empleado como agente de seducción en los poemas de Olga Orozco. Minuciosamente cincelados, en ellos nada se deja al azar, cada palabra ha sido perfectamente colocada para producir en nosotros el efecto deseado. Su ritmo es un ritmo lento, pausado, salmódico, que fluye desde el silencio y la serenidad, y que obliga a sus versos a extenderse hasta formas próximas al versículo. Desde ellos habla con voz profunda, envolvente y tranquila en su desmesura. La letanía de su canto transido nos invita a viajar por ese universo suyo de objetos y seres perdidos que con el encanto de la palabra ansía recobrar. En su poesía visionaria el ritmo nos empuja como oleaje maldito hasta la visión final:

Yo, Olga Orozco, desde mi corazón digo a todos que muero.

[...] De mi estadía quedan las magias y los ritos,

[...] y unos gestos dispersos entre los gestos de otros que no me conocieron.

Lo demás aún se cumple en el olvido,

aún labra la desdicha en el rostro de aquella que se buscaba en mí igual que en un espejo de sonrientes praderas,

y a la que tu verás extrañamente ajena:

mi propia aparecida condenada a mi forma de este mundo ${ }^{16}$.

Ya el primer verso denota una composición casi perfecta. Alternando, como será habitual, pausas cortas con fragmentos más largos, la modulación de «desde mi corazón digo a todos que muero» obliga a reconocer un metro cercano al alejandrino, con sus dos hemistiquios y su cesura en la palabra puente «digo» y sus pautas de acentuación —en la primera y sexta sílaba, y de nuevo, en la tercera y sexta—, con lo que se produce un fenómeno de compensación y el verso cae hacia el final con rotundidad, perfectamente acabado. La rima y la sonoridad, que no es constante y es libre, nos lleva a encontrar palabras (praderas / ajena; sonriente / extrañamente)

15 Arrancadas de su silencio, las palabras son convocadas en la imagen donde, recobrado todo su poder, serán capaces de dar vida de nuevo, engendrarla: «Apenas reconquistan su plenitud, readquieren sus perdidos significados y valores». En cada imagen «lejos de agrandarse, la distancia entre la palabra y la cosa se acorta o desaparece del todo: el nombre y lo nombrado son ya lo mismo»; «El lenguaje indica, representa; el poema no explica ni representa: presenta», en O. Paz (2008), p. 109, 112 y 113; respectivamente.

${ }^{16}$ O. Orozco (2007), p. 77. 
sobre las que se busca crear esa ligazón. Nos coloca directamente ante una musicalidad interna muy trabajada, de manera que la rima es más bien una melodía conseguida a partir de un proceso de acentuación que da ritmo y movimiento al tiempo que no sólo se aferra a los finales de los versos.

El arrullo de la palabra en Olga Orozco nada tendrá que ver con la vehemencia rítmica del desencanto y el cansancio de Oliverio Girondo. La actividad que comenzara en Persuasión de los días y terminara en En la masmédula con lo que Pellegrini denominó la palabra informal ${ }^{17}$, supone una agresión al lenguaje sin precedentes, en la línea más experimental de la poesía. Hay un querer decir violento, una acumulación de materias nauseabundas, putrefactas, descompuestas todavía en el primer libro citado. Materias cuya sola enunciación provocan el asco y la repulsión:
la negra baba rancia que babea esta especie babosa de alimañas por sus rumiantes labios carcomidos por sus pupilas de ostra putrefacta por sus turbias vejigas empedradas de cálculos por sus viejos ombligos de regatón gastado por sus jorobas llenas de intereses compuestos[... $]^{18}$.

Una especie de cólera semántica de la ponzoña despierta en nosotros el atisbo de algo claramente perturbador. Nos sentimos como movidos, traspasados por la rabia girondiana, embestidos por la fealdad de su fiereza. Y lo que, por valor de su significado y forma era, no un delicado y rítmico fluir sino sacudida bruta, tornará, poco a poco, en agitación sonora. El uso de la repetición, el énfasis en determinados sonidos - la ele, la te, la eme - y la cortedad de las palabras en «Mi lu / Mi lubidulia / Mi golocidalove / Mi lu tan luz tan tú que me enlucielabisma / Y me descentratelura» ${ }^{19}$ imprime un ritmo que pone el acento en un precipitarse vértigo a la palabra sola. Girondo centralizará todo su esfuerzo en construir un sentido a partir del sonido y el ritmo con un movimiento más atropellado y discontinuo ${ }^{20}$.

\footnotetext{
${ }^{17}$ A. Pellegrini (1962), p. 32.

${ }^{18}$ O. Girondo (1999), p. 144.

${ }^{19}$ O. Girondo (1999), p. 235.
}

${ }^{20}$ En relación a la poesía más experimental de Girondo deberemos señalar las enormes posibilidades de sugerencia que alcanza por el uso del fragmento y que se encuentran sumamente ligadas a la creación de un ritmo. Posibilidades que ya fueron advertidas por otros autores como Blanchot, quien vería en el fragmento una forma concentrada de decir que al mismo tiempo no lo dice sino que lo esboza, lo mantiene abierto, desde su propia individualidad y en relación con el resto de las unidades, casi como si desde una pluralidad de voces hubiese sido emitido. Respecto al mismo dice así: «considerar al fragmento como un texto reconcentrado que tiene su centro en sí mismo y no en el campo que constituyen con él los otros fragmentos; desatender el intervalo (espera y pausa) que separa los fragmentos entre sí 
Esa manera de acometer contra el lenguaje y la palabra encontrará su equivalente pictórico en pintores como los denominados informalistas en España o expresionistas abstractos en Norte América. Pues esa misma destrucción de la forma para dejar que sea el gesto violento o la huella del pintor lo que deje constancia de sus pulsiones internas tiene mucho que ver con la operación girondiana. Cuando las palabras fallan y las imágenes concisas no traducen, no aciertan a decir, surge la necesidad de buscar otras maneras con que seguir contando la tragedia, como ocurrió, en ambos casos, tras los periodos de conflictos que asolaron el pasado siglo XX. Todos los golpes, laceraciones, cosidos y recosidos que Tàpies, Saura o Millares inflingieran a la tela y a la masa pictórica hallaron su correspondencia en los ataques a la palabra girondiana. Unos y otros comparten igualmente el ritmo como elemento dinamizador, expresión de lo salvaje. Si retomáramos a Wölfflin en este preciso momento, podríamos hablar de un discurso enajenado, consecuencia de un espíritu común contrario a la razón.

Y prosiguiendo con el movimiento, aún incluso en aquellos pintores en los que la figura o la forma no llegara a perderse, como sucedió con Francis Bacon, el uso de las líneas de fuerza iba a ser el recurso con que componer una imagen alucinada, perdida y voraz. En los estudios que realizara el pintor irlandés sobre Inocencio $X$, de Velázquez, la verticalidad de esas líneas tiene un contrapeso débil pero firme en la balaustrada que circunda el espacio central de la figura. Si lo habitual y más efectivo en el arte era recrear ese movimiento a partir de una sensación como de ascensionalidad, de querer ir hasta lo más alto, el movimiento que rige el impulso interno de un poema nunca será lineal sino circular. En la imagen pictórica el espacio concéntrico es un espacio que coarta y sirve también para simbolizar la eternidad de la condena. El hombre representado jamás podrá escapar de su prisión.

Las nociones de circularidad y verticalidad o ascensionalidad resultan sumamente interesantes. Valéry comparó la prosa con la marcha y la poesía con la danza, y Paz les asignó las siguientes figuras geométricas:

La figura geométrica que simboliza la prosa es la línea: recta, sinuosa, espiral, zigzagueante, mas siempre hacia delante y con una meta precisa. De ahí que los arquetipos de la prosa sean el discurso y el relato, la especulación y la historia. El poema, por el contrario, se ofrece como un círculo o una esfera: algo que se cierra sobre sí mismo, universo autosuficiente en el cual el fin es también un principio que vuelve, se repite y se recrea ${ }^{21}$.

y hace de esta separación el principio rítmico de la obra en su estructura; olvidar que esta manera de escribir no tiende a dificultar una mirada de conjunto ni a debilitar las relaciones de unidad, sino a hacer posibles nuevas relaciones, que se exceptúan de la unidad, del mismo modo que exceden el conjunto», en M. Blanchot (1969), pp. 526-527.

${ }^{21}$ O. Paz (2008), p. 69. 
Esa repetición, ese principio que vuelve, no es sino la realización misma del ritmo, movimiento u oleaje que va y viene y que nos deleita y maravilla con su prestigio hechizante, induciéndonos a leer una por una las palabras del poema. Pero es también condición de la poesía como forma perfecta, cerrada en sí misma. Al respecto de esta circularidad, tiene Paz una obra titulada «La calle»:

Es una calle larga y silenciosa.

Ando en tinieblas y tropiezo y caigo

y me levanto y piso con pies ciegos

las piedras mudas y las hojas secas

y alguien detrás de mí también las pisa:

si me detengo, se detiene;

si corro, corre. Vuelvo el rostro: nadie.

Todo está obscuro y sin salida,

y doy vueltas y vueltas en esquinas

que dan siempre a la calle

donde nadie me espera ni me sigue,

donde yo sigo a un hombre que tropieza

y se levanta y dice al verme: nadie $^{22}$.

El movimiento que antes viéramos descrito como tal en la quintilla de Quevedo, sugerido a través de los principios rítmicos y sonoros del habla y más tarde como manifestación del furor interno, será conjurado ahora a partir de la propia dinámica del poema. Ese salto a la otredad o esa revelación de lo otro que supone el poema, de ese personaje que es él y no lo es, que es perseguido por alguien a quien finalmente sigue y es una vuelta o un recaer en sí mismo, lleva implícito un movimiento circular abstracto. $\mathrm{Y}$ es casi una búsqueda, revelación sublime, cuando descubrimos que el que pudiera ser es él. Y sin embargo, el movimiento solipsista no termina de resolver, y la posibilidad del reencuentro queda abolida para siempre. A su lado podríamos colocar cuadros de imágenes dobles, del cuadro dentro del cuadro, inmersas en un universo de referencias metartísticas. Dos mujeres desnudas, de Picasso, viene a tratar un tema similar. Realmente no sabemos si son dos mujeres o tal vez una sea el reflejo especular de la otra. Por la posición de los cuerpos se nos permitiría dudar. Y sin la convención de un posible marco que separe la imagen real de la que es imagen de la imagen, esa duda permanece. ¿Son dos personas distintas?, ¿dos dibujos? o ¿ella y ella misma, su reflejo? Ella y lo otro. Nelson Goodman aludía a la continuidad y la discontinuidad de las formas simbólicas como base de la distinción de lo que ocurre en un texto o en una imagen ${ }^{23}$. La discontinuidad de las

${ }^{22}$ O. Paz (1993), p. 77.

${ }^{23}$ «Nonlinguistic systems differ from languages, depiction from description, the representational from the verbal, painting from poems, primarily through lack of difference -indeed through density (and consequent total absence of articulation)- of the symbol system», en $\mathrm{N}$. 
unidades del poema permite concebirlas y distinguirlas a lo largo del tiempo. La cohesión de todos los trazos en la pintura obliga a abordarla de una sola vez. Si el encuentro con lo otro tenía una origen móvil, circular, en el poema, con aquello de revelación sobrecogedora que tiene el instante final, la pintura, estática, se nos hace extraña desde un primer momento. No es la magia de lo que sobreviene, pero sigue siendo igualmente desconcertante.

Las nociones de continuidad y discontinuidad marcarán el curso de nuestras últimas reflexiones. Pues si durante las vanguardias ya hubo algún intento de registrar el movimiento, descomponiéndolo en sus diferentes fases y recogiéndolas todas en un mismo dibujo o placa fotográfica - Muybridge, Marey, los futuristas-, los intentos que más viva impronta dejaron en nosotros al reflejarlo fueron aquellos que hicieron suya la discontinuidad del texto. Así ocurrió en el cine, así también lo refirió Deleuze: para quien ya no habría que recomponer el movimiento a partir de los instantes privilegiados (poses) sino a partir de instantes cualesquiera (cortes). En las fotografías de Nacho Criado vemos esa composición a partir de las partes que, entendidas como unidades expresivas en sí mismas, son capaces de crear un discurso renovado y altamente sugestivo. Con frecuencia nos las presenta como elementos individuales que forman parte del conjunto de la obra, que tan pronto las podemos apreciar en su extremada singularidad como en su diálogo con cada una de las demás. Son fotografías tomadas, una por una, a los mismos objetos y en los mismos escenarios, pero desde posiciones o ángulos cambiantes. Al ofrecérselas al espectador según un determinado criterio de organización, le obligará a que tome parte y se implique, a que sea él el que recomponga los espacios en blanco, las pequeñas discontinuidades de la historia presentada.

Estrella de Diego reflexionará sobre estos acontecimientos como de territorialización y dilatación del espacio visual, que tendieron a fracturarlo generando un nuevo espacio, esta vez mucho más narrativo. Aunque, en su caso, el estudio se centraría en proyectos artísticos con carácter autobiográfico ${ }^{24}$, hallará, igualmente,

Goodman (1976), p. 226. Con ello Goodman establecía una diferencia de densidad para los diferentes tipos de signos que influía tanto en las cualidades semánticas como sintácticas de sus elementos y ligaba sus significados a las relaciones que se producían entre sus marcas, dentro de un campo que puede ser denso y continuo o lo contrario. A pesar de que para él todos los símbolos surgían de una convención - aspecto no compartido con otros semióticos, que distinguían en función del grado de convencionalidad-, el ejemplo más familiar que daba como sistema simbólico que no es denso ni continuo, que opera a partir de huecos y discontinuidades era, ni más ni menos, que el alfabeto.

${ }^{24}$ Para la autora, los autorretratos convencionales, aquellos que nos remitían a una imagen ideal - lo que a partir de Lacan denominaría como «un yo ejemplar»—, no eran capaces ya de reflejar el carácter móvil de la identidad moderna. Optará por estudiar las formas autobiográficas que trataron de reflejar y convocar a ese yo que fui y ese otro que soy ahora, y que «sólo en el espacio narrativo [volverán a ser] capaces de convivir», en E. de Diego 
en ese hacer como expansivo de las posibilidades del discurso por obra de la interrupción o el silencio, de lo que produce distancia o separación, las vías para el cambio. Era necesario encontrar una estrategia con la que superar el carácter estático y eterno que limitaba a los trabajos pictóricos o fotográficos, en los que, como dijimos, una vez aparecía la imagen, ésta quedaba apresada, detenida para siempre en las formas de lo concreto. En el fondo, esa secuencialidad de la que hablaba Estrella de Diego y la idea de discontinuidad de Goodman vienen a decir lo mismo: el éxito de la pintura y fotografía en relación al movimiento advino cuando éstas encontraron una manera con que fragmentar y sugerir ese antes y después necesario para evocar el paso del tiempo y, por ende, la realización del movimiento (ver Figura 2).
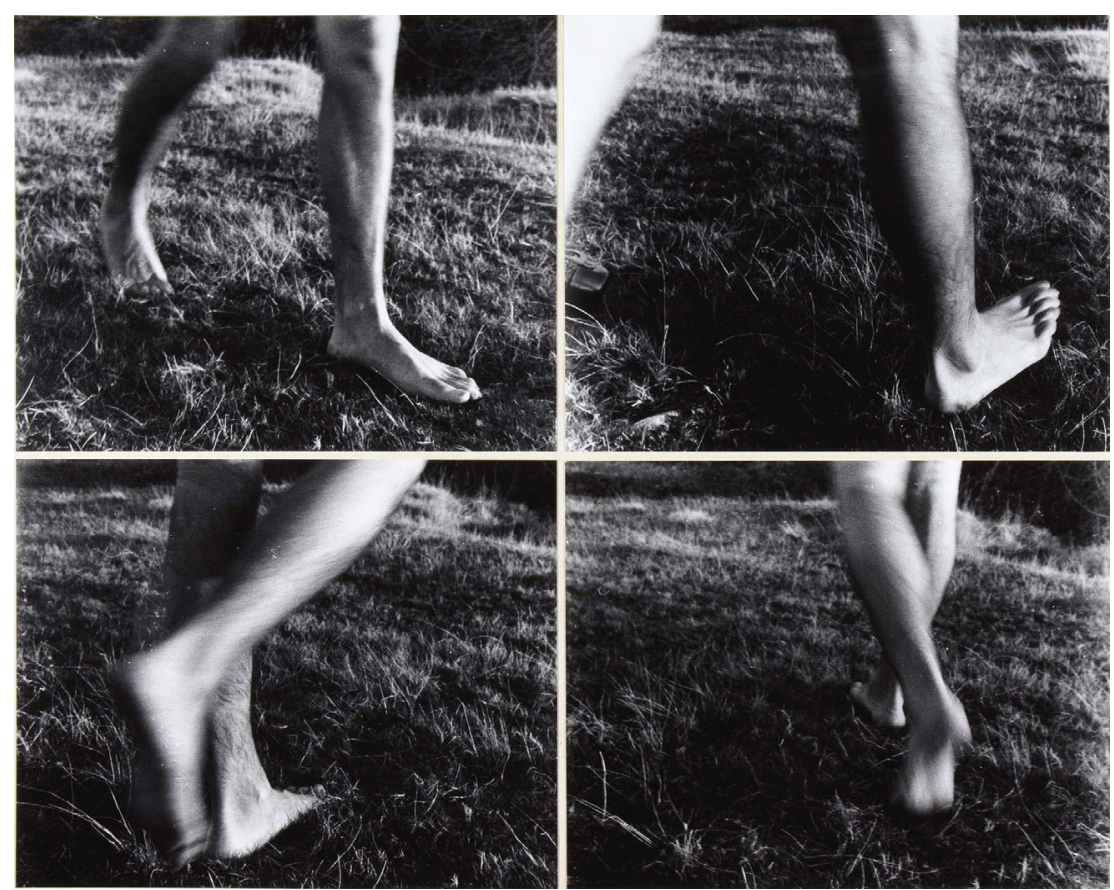

Figura 2. Pasos y recorrido. Nacho Criado, MNCARS, 1974.

(2011), p. 23 y 10, respectivamente. Por ello, para dar cuenta de la realidad plural del sujeto moderno, de ese antes y después que lo define, la autora verá necesario introducir el concepto de la secuencialidad en relación al fenómeno temporal que desea analizar en las obras de carácter pictórico. 
Otras conquistas se produjeron también en el entorno de la poesía que vinieron a suponer el uso de lo visual para reforzar el tema tratado. Apollinaire marcó el camino y otros lo continuaron. Sin llegar a ser un poema pintado o un dibujo a partir de palabras, Blanco, de Octavio Paz, supone un ejemplo en la utilización de lo visual y las características que se le presuponen para apoyar la idea de movimiento y acercamiento de los amantes, sin abandonar nunca la primacía del texto. Concebido originalmente como un único poema, nada más que un texto, en la introducción al libro Ladera este aclara: «este poema debería leerse como una sucesión de signos sobre una página única; a medida que avanza la lectura, la página se desdobla: un espacio que en su movimiento hace aparecer el texto y que, en cierto modo, lo produce». Querrá para él hacer suyas las nociones de continuidad o de no ruptura de la página tras página, que la continuidad de la contemplación permita advertir no sólo simbólica sino físicamente el movimiento. Nos llevará por un «viaje inmóvil» en el cual «el espacio fluye, $[\ldots]$ transcurre como si fuese tiempo» ${ }^{25}$. Pero tampoco será la globalidad del acto pictórico, la que aparece de una sola vez, sino que pretende que sea descubierto, que los principios por los que se hace el tiempo rijan un espacio en el que se cumple su poesía. Aún entraña progresión, un sucederse de imágenes. El espacio dejará de ser mero sostén de la escritura para ser, más que nunca, esencia misma que engendra y determina el poema.

Además de ese movimiento que se aprecia en su conjunto, encontraremos uno especialmente personificado en el encuentro de los enamorados por el que cada columna de versos representa un principio masculino y otro femenino ${ }^{26}$. A las primeras voces que preconizan el deseo, con las columnas aún separadas, seguirá el instante de la unión, interpretada visualmente en un verso en el que todo queda trascendido y el hombre y la mujer son ahora uno:
caes de tu cuerpo a tu sombra no allá sino en mis ojos
en un caer inmóvil de cascada cielo y suelo se juntan
[...]derramada en mi cuerpo yo soy la estela de tus erosiones
tú te repartes como el lenguaje espacio dios descuartizado
tú me repartes en tus partes altar el pensamiento y el cuchillo ${ }^{27}$

\footnotetext{
${ }^{25}$ O. Paz (1998), p. 140.

${ }^{26}$ Podremos reconocer en el poema una serie de temas o motivos que se irán manifestando a través de pautas compositivas distintas y que, permitirán a su vez, varios modelos de lectura. El que aquí enunciamos no es el único y es el que corresponde a ese principio masculino y femenino que en el libro original se iba a representar con dos columnas de color negro y rojo. Trataremos de acentuar la distinción con un uso enfático de la tipografía.

${ }^{27}$ O. Paz (1998), p. 150.
} 
El movimiento «se desata, se esparce» ${ }^{28}$, se vuelve fuerza intensa, principio incesante. Y tras la exaltación llega la pausa, la vuelta a cada uno, recobrando los dos su verdadero nombre y su cuerpo:
contemplada por mis oídos horizonte de música tendida olida por mis ojos puente colgante del color al aroma acariciada por mi olfato olor desnudez en las manos al aire $[\ldots]$ habitar tu nombre despoblar tu cuerpo caer en tu grito contigo casa del viento ${ }^{29}$

El poema opta por representar visualmente la unión amorosa y el principio de movimiento que la alienta para reforzar los contenidos y las imágenes que el poeta desea recrear. El espacio se convierte ya en elemento generador de ritmos e imágenes, obligando al poema a tomar recursos que en un principio parecían no pertenecerle. Se trata de una incursión en el reino de lo tangible, de lo físicamente también reconocible, aunque sin abandonar la lógica del texto. Un signo que hace extensible su poder de evocación a la manera de las fotos de Nacho Criado, intentando sobrepasar los estrictos límites que separan las nociones del arte y la literatura, y lo que corresponde a cada una. Porque aunque espacio-tiempo, corporeidad-representación mental, lo externo-interno, ojo-oído, silencio-elocuencia, continuidad-discontinui-dad del símbolo suelen ser algunas de las características sobre las que se gestan las más rígidas oposiciones, cuando la pintura y la poesía trataron de hacer suyas las dimensiones o las cualidades antes vedadas, demostraron, no sólo la inviolabilidad de estas categorías, sino el factor de enriquecimiento que tales conquistas supusieron.

\section{OBRAS CITADAS}

BARTHES, Roland: La aventura semiológica, Barcelona, Paidós, 2009.

BLANCHOT, Maurice: L'Entretien infini, París, Editions Gallimard, 1969.

DELEUZE, Gilles: La imagen-movimiento. Estudios sobre cine 1, Barcelona, Paidós, 2012.

DIEGO, Estrella de: No soy yo. Autobiografía, performance y los nuevos espectadores, Madrid, Siruela, 2011.

GIRONDO, Oliverio: Obra completa, Raúl Antelo (ed.), Madrid, Allca XX, 1999.

GOODMAN, Nelson: Languages of Art, Indianápolis, Hackett, 1976.

MitchelL, W. J. Thomas: Iconology: image, text, ideology, Chicago, University of Chicago Press, 1992.

Orozco, Olga: Obra poética, Buenos Aires, Corregidor, 2007.

${ }^{28}$ O. Paz (1998), p. 154.
${ }^{29}$ O. Paz (1998), p. 158. 
PAZ, Octavio: Libertad bajo palabra, Madrid, Fondo de Cultura Económica, 1993. : Ladera este, Barcelona, Galaxia Gutenberg, 1998.

: El arco y la lira. El poema. La revelación poética. Poesía e historia, México, Fondo de Cultura Económica, 2008.

Pellegrini, Aldo: Oliverio Girondo, Buenos Aires, Ediciones Culturales Argentinas, 1962.

Quevedo, Francisco de: «De Dafne y Apolo. Fábula», en Pedro Espinosa, Primera parte de Flores de Poetas ilustres de España, Inoria Pepe Sarno y José María Reyes Cano (eds.), Madrid, Cátedra, 2006, pp. 199-202.

VALÉRY, Paul: Introducción a la poética, Buenos Aires, Rodolfo Alonso Editor, 1975.

VARela, Elena, Moíno, Pablo, y JaURALDe, Pablo: Manual de Métrica Española, Madrid, Castalia, 2005.

WöLfFLIN, Heinrich: Renacimiento y Barroco, Barcelona, Paidós, 1986. 